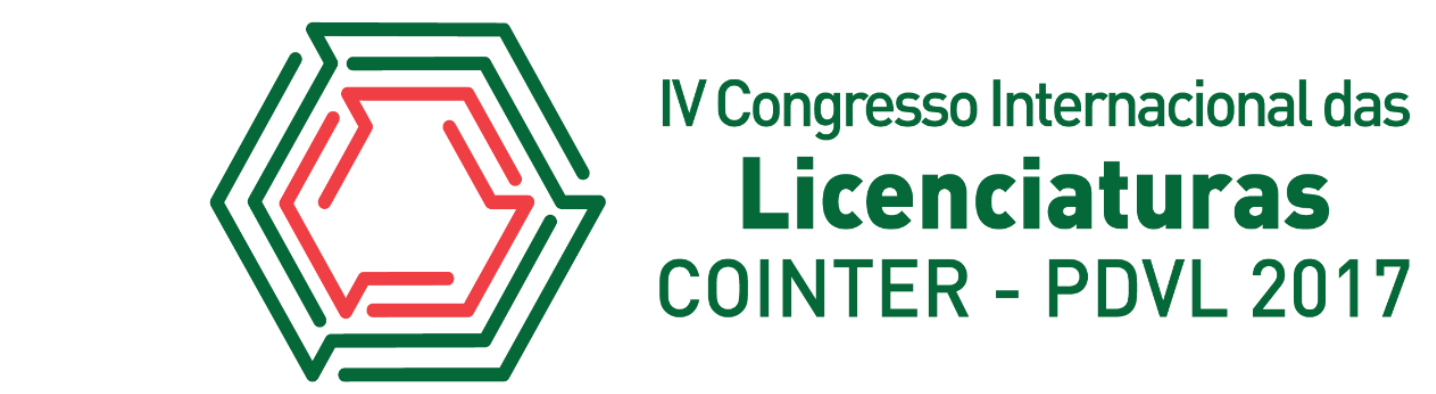

\title{
IMPORTANCIA DO MONITOR NA DISCIPLINA MANEJO E CONSERVAÇÃO DE PASTAGENS AGROECOLÓGICA
}

\author{
Apresentação: Pôster
}

\begin{abstract}
Julielson de Souza Silva ${ }^{1}$; Lidiane Marques Lima Santos²; Amanda Fabrício Dantas ${ }^{3}$; Ana Patrícia Bezerra Almeida ${ }^{4}$
\end{abstract}

\section{Introdução}

O monitor é considerado um agente do processo ensino-aprendizagem, capaz de intensificar a relação professor-aluno-instituição (Natário, 2007). Uma formação acadêmica de qualidade é essencial para que o discente possa tornar-se um profissional capacitado.

Algumas medidas foram implantadas visando fornecer tal constituição aos estudantes de ensino superior, uma delas é a Lei no 9.394 de 20 de dezembro de 1996, que estabelece as diretrizes e bases da educação nacional (LIMA et al., 2006). A monitoria acadêmica é instituída em seu Art. 84: “os discentes da educação superior poderão ser aproveitados em tarefas de ensino e pesquisa pelas respectivas instituições, exercendo funções de monitoria, de acordo com seu rendimento e seu plano de estudos" (BRASIL, 1996, p. 26).

Santos e Lins (2007) destacam a relevância da iniciação à docência como uma das formas de, desde cedo, desenvolver, em uma parcela dos alunos da graduação, o gosto pela atividade docente. Deste modo pode-se afirmar que o programa de monitoria se apresenta atualmente como um importante espaço no qual pode-se criar bases de uma formação voltada para a docência.

Para Soares e Lins (2008), a monitoria consiste numa atividade acadêmica de natureza complementar, na qual o aluno tem a oportunidade de desenvolver e ampliar os conhecimentos adquiridos na academia por meio do apoio ao docente na condução da disciplina. Para Soares et al., (2001), o projeto de monitoria visa propiciar a interdisciplinaridade e unir teoria e prática durante as atividades desenvolvidas, auxiliando o docente, facilitando e maximizando o aprendizado dos alunos, despertando o interesse na importância da disciplina acadêmica.

\footnotetext{
${ }^{1}$ Bacharelado em Agroecologia, UFPB/CCHSA, julielsontecrn@hotmail.com

${ }^{2}$ Bacharelado em Agroecologia, UFPB/CCHSA, lidianemarquesagro@gmail.com

${ }^{3}$ Licenciatura em Ciências Agrárias, UFPB/CCHSA, amandadantas550@gmail.com

${ }^{4}$ Professora Dr.a , UFPB/CCHSA, bezerraapa@yahoo.com.br
} 
A disciplina Manejo e Conservação de Pastagem Agroecológica, a qual está inserida no projeto de monitoria, é obrigatória do curso de Bacharelado em Agroecologia, e permite aos alunos o estudo detalhado das plantas forrageiras, manejo racional das pastagens e os métodos de conservação das pastagens. Abordando conteúdo referente ao pastoreio racional Voisin e as experiências de produtores de pastagens agroecológicas.

O projeto de monitoria se deu devido aos altos índices de reprovação, verificados nos últimos semestres (2013.2 e 2014.2), no qual estava acarretando em elevados índices de evasão no curso de agroecologia, caso que não foi visto em anos posteriores, 2015.2 e 2016.2 após a inserção dos monitores na disciplina. O objetivo deste trabalho é mostrar a importância da monitoria nos cursos de bacharelado em agroecologia.

\section{Fundamentação Teórica}

A monitoria é um procedimento pedagógico que apresenta grande relevância na formação do discente, pois proporciona o aprimoramento intelectual e social através da relação com o professor, com as atividades didáticas e com os outros alunos. Esse contato permite a troca de conhecimentos e experiências entre os sujeitos envolvidos tornando o processo enriquecedor, além da articulação entre teoria e prática, ação esta considerada indissociável aos níveis de aprendizagem (LINS et al, 2009). De acordo com Santos et al., (2012), a referida prática complementar de ensino pode se concretizar nos diversos cursos de graduação, desde que elaborado e aprovado projeto contendo as disciplinas e respectivos orientadores.

A função de monitor é designada aos alunos graduandos, mediante prova específica que vai demonstrar a aptidão em determinada disciplina, para então o aluno aprovado exercer as atividades técnico-didáticas propostas (LINS et al, 2009). Luckesi et al., (1998), afirma que a esfera do ensino superior deve objetivar-se como centro de debates fundamentados na cientificidade e seus métodos, para que assim o conhecimento seja apreendido e transmitido de modo crítico.

O monitor realizará tarefas junto ao professor orientador descritas como planejamento de aulas, auxílio na realização de trabalhos, preparação de material didático e atividades em sala, interação com os alunos monitorados, avaliação do plano de atividades junto ao orientador. Dessa maneira, a monitoria configura-se não só como finalidade complementar na formação acadêmica, mas como uma experiência ao aluno no âmbito da docência, preparando-o ao magistério, caso seja o seu interesse maior (SANTOS et al., 2012). 


\section{Metodologia}

O Projeto de monitoria foi desenvolvido no Campus III, da Universidade Federal da Paraíba - UFPB, considerando a disciplina Manejo e Conservação de Pastagens Agroecológica (MCPA), integrante da grade curricular do curso de Bacharelado em Agroecologia.

As atividades desenvolvidas pelos monitores (as) na disciplina MCPA, é um componente curricular obrigatório do curso de graduação. As atividades de monitoria foram desenvolvidas com base no plano de trabalho desenvolvido pela docente.

A monitoria foi dividida em dois momentos: o primeiro momento ligado diretamente ao professor-orientador, auxiliando no planejamento e execução das atividades junto aos alunos da disciplina, através do aprofundamento teórico previamente selecionado pelo professor. O segundo momento se deu pelo o contato aluno-monitor junto aos discentes da disciplina, tendo como finalidade auxilia-los no esclarecimento de dúvidas e/ou aprofundamento da temática desenvolvida na disciplina, assim, ajudando-os no esclarecimento e no acompanhamento de dúvidas inerente aos conteúdos programáticos e exercícios lecionado pelo professor-orientador.

Principais atividades desenvolvidas na monitoria; acompanhamentos das aulas, auxiliando nas discussões, organização de material didático para o desenvolvimento das atividades; Planejamento das atividades desenvolvidas concomitante aos discentes (aulas, seminários, atividades extraclasses, visitas técnicas); os horários foram planejados para esclarecimentos técnicos e práticos; Desenvolvimento de atividades teóricas e práticas.

\section{Resultados e Discussões}

A monitoria permitiu uma maior interação entre o monitor e os discentes nas discussões e também na organização de material didático necessário para o desenvolvimento das atividades; Planejamento das atividades de monitoria desenvolvidas junto aos alunos como (aulas, seminários, atividades extraclasses, visitas técnicas); disponibilidade de horários para planejamentos e esclarecimentos técnicos e práticos; Desenvolvimento de atividades teóricas e práticas.

O Programa de Monitoria Acadêmica gera benefícios para a formação do monitor, como apontam Cordeiro e Oliveira (2011), essa experiência é necessária para os alunos que possuem dúvidas sobre a formação posterior, assim como para os alunos que desejam seguir a prática docente. Ramos et al., (2012), destacam alguns benefícios da monitoria, a saber: inserção do aluno monitor em ensino, pesquisa e extensão, auxílio aos alunos monitorados e ao professor. 
O primeiro refere-se ao incentivo ofertado pelo programa ao monitor, onde o mesmo precisa estar sempre se atualizando sobre os conteúdos passados, estudando e pesquisando novos conteúdos também. Pontos positivos apresentados por Soares e Santos (2008), em que a monitoria possibilita através da relação entre docente e monitor, o aprimoramento da qualidade de ensino da disciplina, bem como estimula o exercício da pesquisa acadêmica, permitindo uma contínua associação entre teoria e prática. A monitoria contribui para um melhor planejamento e execução das atividades relacionadas a disciplina 'Manejo e Conservação de Pastagem Agroecológica. Seguindo as orientações do professor da referida disciplina, e sempre supervisionados por este, o monitor minimizou as dúvidas de alunos sobre o conteúdo ministrado pelo docente; auxiliou o professor na elaboração e aplicação de material didático.

Com o desenvolvimento das atividades utilizadas na monitoria, constatou-se que os alunos ficaram mais motivados, o que facilita, desta forma, a aprendizagem dos conteúdos teóricos, práticos e experimentais ministrados. Nessa concepção, a atividade de monitoria demonstrou-se bastante eficaz. As atividades desenvolvidas têm contribuído significativamente na redução dos índices de desistências, trancamentos e reprovações (Gráfico 1).

Gráfico 1. Notas dos alunos referentes aos períodos 2013. 2, 2014. 2 e 2015.2

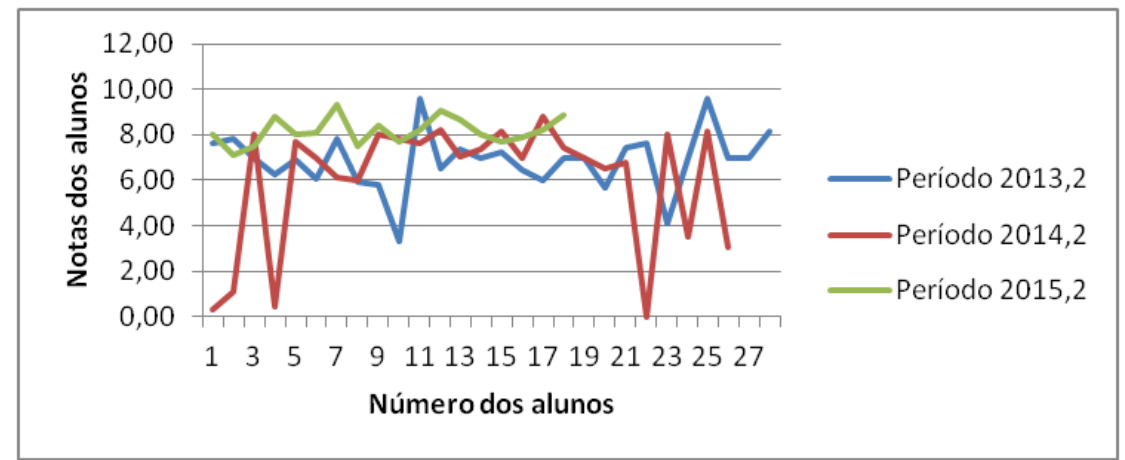

O gráfico 1, notas dos alunos nos períodos 2015.2 e 2016.2, onde mostra eficácia da monitoria obtendo índices elevados de notas. Onde no período 2016.2 as três notas baixas se deram por reprovação em consequência do número de faltas, desistência e trancamento, ou seja, todos que cursaram a disciplina foram aprovados por media. Apenas dois alunos dos 27 foram reprovados.

Gráfico 2. Notas dos alunos referentes aos períodos 2015.2 e 2016.2.

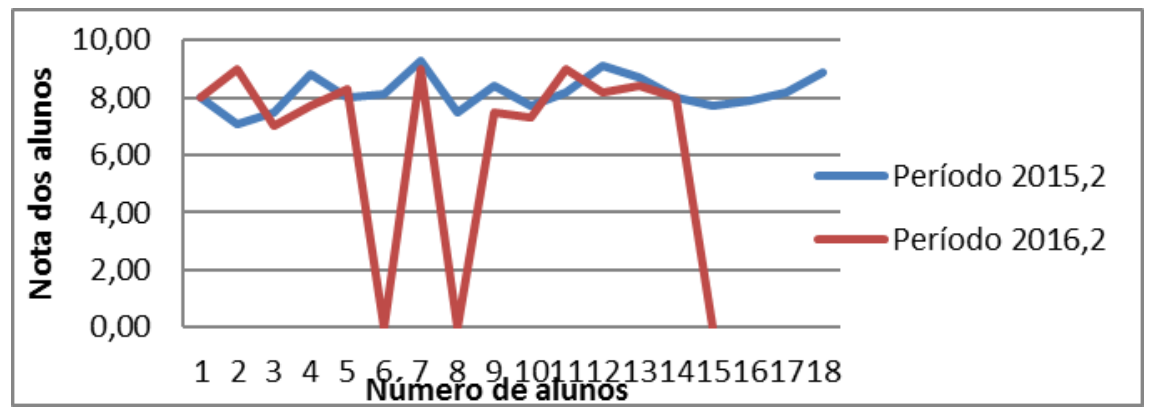


O monitor é de fundamentar importância para auxiliar na supressão das dificuldades, levando os alunos a um melhor desempenho profissional e consequentemente, a um bom rendimento na disciplina.

Assis et al (2006) argumentam que a monitoria se configura como uma iniciativa relevante no ambiente universitário, pois tais atividades envolvem o desenvolvimento de ações que fortalecem a formação do aluno em diferentes dimensões, ao mesmo tempo em que lhe proporciona a possibilidade de ampliar o conhecimento, desenvolvendo suas habilidades e aptidões para o campo do ensino.

\section{Conclusão}

A monitoria mostrou ser de grande importância para a disciplina de manejo e conservação agroecológico de pastagens (MCPA), promovendo um melhor aprendizado dos monitores e dos discentes, logo revertendo o índice de evasão, contribuindo com o ensino-aprendizagem do curso.

\section{Referências}

ASSIS, F. et al. Programa de Monitoria Acadêmica: percepções de monitores e orientadores. Revista de Enfermagem da UERJ, v. 14, n. 3, p. 391-397, 2006.

BRASIL. Lei $\mathbf{n}^{\text {o }} \mathbf{9 . 3 9 4}$ de 20 de dezembro de 1996.Disponível em <http://portal.mec.gov.br/seesp/arquivos/pdf/lei9394_ldbn1.pdf>. Acesso em: 1 de out. 2016.

CORDEIRO, A. S.; OLIVEIRA, B. P. Monitoria acadêmica:a importância para o aluno de licenciatura em química. 2011. Disponível em: 〈http://annq.org/eventos/upload/1325330899.pdf>. Acesso em: 2 out. 2016.

CHAVES, D. M.;VASCONCELOS, A. C. T. Educação superior: monitoria acadêmica como modalidade de ensino.

CORDEIRO, S. A. et al. Monitoria acadêmica: a importância para o aluno de licenciatura em química.Disponível:http://annq.org/eventos/upload/1325330899.pdf. Acessado: 28.09.2017.

Natário, E. G. (2007). Monitoria: um espaço de valorização docente e discente Anais do $3^{\circ}$ Seminário Internacional de Educação do Guarujá, 2007 (Vol.1, pp.29). Santos: Editora e Gráfica do Litor.

SILVA, S. P. C; FURLANETTO, L. E; GONÇALVES S. H. Monitoria acadêmica: a importância para o aluno de licenciatura em química.Disponível em:>http://annq.org/eventos/upload/1325330899.pdf. Acessado em 28 de setembro de 2017.

SOARES, M. A. A. A monitoria como subsídio ao processo de ensino-aprendizagem: o caso da disciplina administração financeira no CCHSAUFPB. Disponível: www.prac.ufpb.br/anais/xenex_xienid/xi_enid/monitoriapet/ANAIS/Area4/4CCHSADCSAMT04.pdf Acesso em: 13.08.2011. 